\title{
Patient online record access - a global perspective
}

This article was published in the following Dove Press journal:

Patient Intelligence

29 July 2015

Number of times this article has been viewed

\author{
Brian Fisher \\ PAERS Ltd., London, UK
}

Correspondence: Brian Fisher

100 Erlanger Rd, London SEI4 5th, UK

Tel +447949595349

Email brianfisher36@btinternet.com
Abstract: Online patient record access now has quite a long history, mainly in the UK, Europe, and North America and we can see the benefits and risks more clearly. This paper explains why the idea is spreading round the world. The benefits are clear to patients and practices. Resistance, mainly from doctors, remains, but seems to subside once systems for record access are in place. Record access has risks, described here, but most can be minimized. The process shifts the balance of power between clinicians and patients - and developments are likely to drive that further.

Keywords: record access, patient empowerment, e-health, IT, shared decision-making

\section{Introduction}

It is a truth now universally acknowledged that online access to your own health record makes sense. You cannot understand and use your finances without access to your bank account: the same surely applies to your health and health care.

This paper offers an overview of record access (RA); why it is seen as important and useful; the common objections to it and what the future probably holds.

\section{What does RA mean?}

There are basically two kinds of access to your own health record. One is called "tethered RA". This means access to your more or less real-time existing record: you see the whole or part of what has been written about you. This is usually through the primary care sector, but not always.

The other kind of access is called the "Personal Health Record". This usually assumes access to your real-time record (though not always), but allows more user involvement. This can include the ability to upload your own data to a personal record, which can subsequently be shared with clinicians and others; can link many different sources of your data; enables the user to hide parts of the record from different people; enables the user to write into their record, so that it becomes a resource shared between clinician and patient.

The technical functionality and usability of the system has a big impact on its usefulness and its ability to alter the behavior of patient and clinician. For instance, some systems enable users to easily link diagnoses and other coded data to information leaflets online. Similarly, some systems link test results with pathology sites that explain the general meaning of the test. And some systems enable access to the clinician's comments on your specific test result. All of these transform data 
into information and help users understand more of what they read.

\section{Global spread}

Tethered RA is often part of a wider offering of patient-facing online services such as booking appointments, ordering repeat prescriptions, and secures messaging which is like email, but within the secure health sector IT system. All these approaches need to be aligned to common medical practice in each country. For instance, some countries would expect to review prescriptions every time they are issued. These are seen as first steps to harnessing the power of the web for patient-centric health systems.

RA is happening across the world. The US probably has the most experience, through organizations such as Kaiser Permanente ${ }^{1}$ and the Veterans' Association. ${ }^{2}$ In some countries coverage is more or less universal, such as in Estonia. ${ }^{3}$ In others it is patchy. Some countries are enabling it through the private sector, others through a mix of private and public. In the UK, where I come from, the government is underwriting the cost of RA and paying a few accredited companies to compete to offer patient-facing services. ${ }^{4}$

In Australia, there was resistance to full RA from doctors in 2013. The government has recently prioritized RA and patients are now being encouraged to sign up at no charge.

\section{Why is RA becoming popular?}

Countries and health organizations offer RA for both moral and practical reasons.

\section{RA increases health service capacity}

There is evidence that RA saves appointments and telephone calls in primary care. Based on real use in two very different English general practitioner (GP) practices, the data suggest that, if $30 \%$ of the practice population used RA at least twice a year, the practice would save $10 \%$ of appointments and hundreds of telephone calls. ${ }^{5}$ In Kaiser, combining RA and secure messaging with patients reduced appointments by $10 \%$ and telephone calls to primary care clinicians by $14 \%{ }^{6}$

Booking appointments and prescriptions online frees staff. Secure messaging may save appointments in its own right, too.

\section{RA will make money}

The UK government is convinced that RA is one of a range of online innovations that will encourage growth and export markets, in the same way as online banking. It is underwriting RA in the National Health Service (NHS) in England because it sees it as a future generator of revenue. That is why it was the Treasury which, in the UK, laid down the rule that anyone who wants it will be able to have RA from April 2015.

\section{Increased safety}

Real world experience with RA suggests that it is safer in many ways. Patients can correct the record - often they are the only people who know what really happened after the event. Patients can share their data with others, enabling integration and speeding up processes, compensating for delayed transfers of information and lost data. ${ }^{7}$

\section{Convenience}

Unpublished data suggest that patients save a lot of time using online access and other patient-facing services. Avoiding practice visits saves petrol and is more sustainable. Secure messaging is potentially efficient as an asynchronous process.

\section{Trust}

There is good evidence that RA helps build trust and improved relationships between practices and patients. ${ }^{8}$ Users feel reassured that clinicians trust them enough to share intimate vital data with them, data that may not be easy to understand or to deal with.

\section{Does RA improve health outcomes?}

There is little evidence on this. We do not know, for instance, if RA helps patients with diabetes control their blood sugar better. Nor if cardiac failure is better controlled. There is some evidence that people who have RA comply with medication better than those who do not. ${ }^{9}$

\section{Moral imperative}

There is a strong ethical aspect to RA. The data are about you - you should have the right to see what is written about you and, if necessary, challenge it. Health services are often opaque to their users and RA offers a window onto the thinking, the opinions, and the management of your care. Evidence is good that RA helps people feel more in control and more aware of why things are being done. ${ }^{10}$ It becomes part of shared decision-making and it assists with self-care.

\section{Issues of power}

Related to moral considerations are those of power. It seems clear that RA shifts the balance of power toward the patient. The clinician is no longer in total control of the data which, 
quite apart from their expertise, give them a clear edge in framing problems and solutions. It allows routine sharing of details such as test results which means that users can be more involved and more able to explore patterns in their symptoms and their care.

\section{Resistance, power, principles, and practicalities}

Across the world, clinicians are skeptical and worried about RA. In the UK, they have fought a long battle against it. Apart from Estonia, doctors in particular have ranged many arguments against RA. Some are important and difficult to counter, some are countered by evidence and experience.

\section{Coercion}

Coercion, for instance being forced by your spouse to reveal your record or a teenager being bullied by their parents to reveal whether they were on contraception, is obviously unacceptable and often illegal. Research suggests that although coercion appears to be widespread the NHS and its clinicians are rarely aware of it.

Women's groups in particular are concerned that RA offers yet another avenue for coercion and that it will be difficult to protect victims. The size of the problem of coercion through RA is unknown. Despite the data on frequency, experience from the US and other countries is that it does not appear to be a problem. However, of course, this may be because no one knows that it is happening.

There may be some technical fixes for this problem, for instance the ability for a patient to surreptitiously switch off the system.

The enrollment system may mitigate the problem by allowing access only after users who sign up accept the risk and are advised to tell the practice if they are being coerced, in which circumstance the practice can switch off their access. In addition, they are advised not to enroll if they are at risk of coercion.

\section{Insurance companies}

Insurance companies in many countries use clinicians, by sharing their patient data, to make more accurate assessments of their customers' liabilities to illness. In the UK, clinicians, who are paid for this service, can hide those aspects of the record that may be prejudicial to the patient.

There is a worry that companies may use the route of RA to go directly to the patient and bypass the clinician's benign release of information. This would financially penalize the doctor, but also enable the company to drive a much harder bargain with the patient.

This is illegal in the US, but not (yet) in the UK. We do not yet know whether this will be a significant issue globally.

\section{Third party data}

It is difficult to exclude illegal third party data from view by the patient. This has been a longstanding concern of both system providers of RA and clinicians. The best protection is to promote good recording practice by clinicians, so that they are aware of the legal requirements with regard to third party data. In addition, many systems do not allow patients access to their free text or their letters before the date at which the patient begins having access. This results in almost negligible (but not zero) risk of exposure to third party data.

In essence, clinicians and patients have to accept that there will be some risk in offering RA. That risk is heavily outweighed by the benefits in most people's eyes - but it is the clinician who will almost certainly have to carry the can for any breach.

\section{Power}

Often unspoken, the issue of power may be behind many professionals' concerns. As noted earlier, RA shifts the balance of power through information, challenging to some extent a paternalistic position. In the future, there may be many "apps" linked to the record that enable patients to do more and take more decisions on their own. It may be that doctors see ourselves as benign dictators of care. We feel that we understand what is best for our patients. We are not comfortable with our decisions being influenced or contaminated by patients' own wishes and demands, even if there is evidence of benefit. RA is a conduit for shared decision-making and it may be that some doctors (and it tends to be doctors rather than nurses) feel profoundly uncomfortable with this trend.

\section{Writing notes differently}

Many clinicians are concerned that they will have to write their records differently so that patients can understand them better. This may take more time and effort and may change the nature of the record.

The record is both a technical and a medico-legal document and primarily a communication with other clinicians. Any change to recording must not threaten or dumb down those functions. Nonetheless, there may be many ways of writing that could make the data easier for lay readers to understand without threatening efficacy: "stroke" instead of "CVA" (cerebrovascular accident) for instance. 
At least two studies have suggested that patients feel they understand $75 \%$ of what they read. ${ }^{8}$ So a requirement to write differently may not actually be very necessary or important.

\section{More work?}

The commonest objection to RA by doctors is that it will result in more work for them and reception staff. In particular, they are concerned that many patients will misunderstand unimportant or irrelevant information in their record and contact the practice frequently.

Experience suggests that setting up systems for enrolling patients can be somewhat burdensome at first, but, once established, the process becomes routine and takes little time. ${ }^{11}$ A study looked at this in detail in two differently organized English GP practices. It took into account the set-up and other administration time. It showed that, although some patients did take up more time as a result of RA, the overall outcome showed significant savings in appointments and telephone calls. ${ }^{5}$

\section{Security}

Both clinicians and users have concerns about the security of their data, highlighted by the Snowden revelations. To date, security breaches specifically of RA have not been a problem. There continue to be concerns that, through legal processes, outside agencies may obtain access to personal data. This has not happened in the RA field. In the UK there has been a national outcry at evidence that government held health data have already been passed to the private sector. Many remain concerned that this may continue to happen with care data, an approach to harnessing NHS health information for research and planning.

\section{Balance is shifting}

It seems that, over the years, grass-roots experience shows that many of these issues are far less of a problem than our risk-averse doctors expect. At the same time, evidence of substantial benefit for patients and practices is beginning to change opinions. In the UK, however, the biggest driver is the decision by the government to mandate the option for everyone in England.

\section{Beyond RA}

It is now clear that RA is only a first step. Indeed, it may be that it has most impact when part of a more comprehensive package of patient-facing services as outlined earlier. In any case, avenues that take us beyond tethered RA are becoming clearer. These ideas have enormous potential to improve care, improve convenience, efficiency and safety and possibly improve health outcomes. Who knows what the future will hold?

\section{Interactive record}

The accessible record can become an interactive portal through which the patient can do much more and interact with their health service. It becomes possible for the process of RA to become a vehicle for automated social marketing. For instance, smoking cessation messages can arrive in the record to be seen whenever the patient logs in to make an appointment, order a repeat prescription, send a message or look at their record - at the very point where they are activated to use their health service.

Smoking cessation messages will only go to smokers; messages on weight reduction only to those above a body mass index set by the practice, or the health organization or public health; advice on sickle-cell only to those with the disease.

In addition, the patient can set RSS (rich site summary) feeds on their portal so that they receive up to date information from national charities about the conditions that are relevant to them.

They can have on their portal a route to a national database such as NHS Choices; or a direct route to sites that enable them to make comments about a service; or be able to report drug side-effects or interactions to the relevant national body.

The portal becomes a two-way channel from which everyone benefits.

\section{Third party "apps"}

Some systems will make it easy for third party "app" developers to access aspects of the record, securely and anonymously, to offer useful new functionality. A patient might be automatically shown local voluntary agencies that could offer support and networks relevant to their illnesses or conditions. A cardiology "app" may be able to help patients improve their health by populating an "app" with their realtime accurate lipid and blood pressure data, thus becoming a personalized support.

\section{Adding to the record}

Fitness data, home blood pressure data, peak flow readings all could be added to the record to be shared with the clinician. No one wants excessive and inappropriate information, so there would need to be ways of moderating the input. 
Another useful application could be a jointly produced care plan which sets out how the care system will support a patient in dealing with their diabetes or any other long-term conditions they may have. The clinician fills in their section and the patient theirs. It becomes a jointly produced working document that both can alter according to circumstances, underpinning shared decision-making and self-care.

\section{Online conversations}

The record could link to online face-to-face conversations, for instance through Skype.

\section{RA abuse}

It is essential that developments in the field involve patients, citizen groups, and organizations that protect transparency and confidentiality. Although the progress toward RA is so far a very positive one for patients and health systems alike, there are potential risks to all. We do not want to find ourselves in the position of the below example:

\section{https://www.youtube.com/watch?v=RNJ19EEcsoE}

\section{An example of an RA system}

Below are three examples of systems that enable RA and more. Here you can see how different RA systems are summarized, as well as a new option - holding data you generate yourself about your health, such as your BP, being held securely for you and being shared with your GP if you want.

- https://www.youtube.com/watch?v=PnYUUTHBa6k

- https://www.youtube.com/watch?v=LeyaHy7mv6U

- https://www.youtube.com/watch?v=15XdPNOuFxg.

\section{Conclusion}

Many countries are either benefiting from RA or are about to. We are on the brink of radical new approaches to care that could enable significant improvements in safety, convenience, and efficiency. There are few technical problems to overcome - the main hurdles are cultural and professional. Like all health interventions, RA will never be risk-free, but it seems clear from the evidence and experience around the world that benefits substantially outweigh risks. We look forward to developments by health services, patients, providers, and "app" developers.

\section{Disclosure}

Dr Fisher is a co-director of PAERS Ltd, a provider of online record access to the UK NHS. He has carried out research in the field, funded by the UK Department of Health. The author reports no other conflicts of interest in this work.

\section{References}

1. ehow.com [homepage on the Internet]. Feigenbaum E. How Do I Get Kaiser Permanente Health Records? Available from: http://www. ehow.com/way_5705232_do-kaiser-permanente-health-records_.html. Accessed May 26, 2015.

2. United States Department of Veteran Affairs [homepage on the Internet] Welcome to my HealtheVet. Available from: https:/www.myhealth. va.gov/index.html. Accessed May 26, 2015.

3. e-estonia.com The Digital Society [homepage on the Internet]. Electronic Health Record. Available from: https://e-estonia.com/component/electronic-health-record/. Accessed May 26, 2015.

4. Health and Social Care Information Centre [homepage on the Internet]. Patient Facing Services. Available from: http://systems.hscic.gov.uk/ gpsoc/services/pfs/index_html. Accessed May 26, 2015.

5. Fitton C, Fitton R, Hannan A, Fisher B, Morgan L, Halsall D. The impact of patient record access on appointments and telephone calls in two English general practices: a population based study. London J Prim Care (Abingdon). 2014;6(1):8-15.

6. Zhou YY, Garrido T, Chin HL, Wiesenthal AM, Liang LL. Patient Access to an Electronic Health Record With Secure Messaging: Impact on Primary Care Utilization. Am J Manag Care. 2007;13(7):418-424.

7. Fisher B, Bhavnani V, Winfield M. How patients use access to their full health records: a qualitative study of patients in general practice. J R Soc Med. 2009;102(12):539-544.

8. Bhavnani V, Fisher B, Winfield M, Seed P. How patients use access to their electronic GP record - a quantitative study. Fam Pract. 2011; 28(2):188-194.

9. Ross SE, Moore LA, Earnest MA, Wittevrongel L, Lin CT. Providing a web-based online medical record with electronic communication capabilities to patients with congestive heart failure: randomized trial J Med Internet Res. 2004;6(2):e12.

10. Fisher B. Patients' access to their electronic record: offer patients access as soon as you can. Br J Gen Pract. 2013;63(611):e423-e425.

11. Pagliari C, Shand T, Fisher B. Embedding online patient record access in UK primary care: a survey of stakeholder experiences. JRSM Short Rep. 2012;3(5):34.
Patient Intelligence

\section{Publish your work in this journal}

Patient Intelligence is an international, peer-reviewed, open access journal that characterizes and measures the central role of patient behavior and intention in optimizing healthcare management in all areas of disease and complaint types. An improved understanding of patient intelligence coupled with predictive analysis helps an organization contribute more effectively to achieving better outcomes.

\section{Dovepress}

The journal is characterized by the rapid reporting of reviews, original research, methodologies, analytics, modeling, clinical studies and patient surveys across all disease areas. The manuscript management system is completely online and includes a very quick and fair peer-review system. Visit http://www.dovepress.com/ testimonials.php to read real quotes from published authors. 